\section{Neonomads: Between Education and Practice}

Patrick Rhodes

American University of Sharjah

Gregory Thomas Spaw

American University of Sharjah
This paper examines the inherent intermediary realities of designbuild within a continuum of academia and practice through the presentation of a series of "in-betweens" associated with a year-long design-build studio, a mobile shelter and research station for the Sharjah Environment and Protected Areas Authority (EPAA) sited within the extreme climatic conditions of the Arabian Desert. It analyzes a set of liminal, cultural, and environmental conditions and how they defined the design process; the way in which we engaged the community; and the resulting architecture as an assessment of the studio experience from the conceptual through to the deployment of built work. The impetus for the studio was a fascination with the Empty Quarter of the Rub' al Khali, one of the most isolated places on Earth and until recently referred to as "terra incognita", 1 and the intersection between the disappearing Bedouin culture and the rapidly developing and modernizing culture of the United Arab Emirates. For thousands of years, the Bedouins have traversed the Arabian deserts and are the only masters of their more than 650,000 square kilometers of ancient sands. ${ }^{2}$ The first foreign explorers were not able to penetrate the Quarter until 1931, with the first accurate Western maps made by Thesiger between 1946 and 1950. ${ }^{3}$ Since then, only a few extreme adventurers have attempted its crossing, leaving the rest of us to wonder at its edge.

When Wilfred Thesiger explored the Empty Quarter between 1946 and 1947, he went for practical, geographic, and diplomatic purposes, but he came back with an education about a little known place, people, and way of life. Thesiger found himself at a crossroads between histories, ecologies, ideologies, and identities at a time when the rest of the world was on the cusp between the second of two great global conflicts and the path toward peace. By his own admission, his time in the desert "radically transformed" his worldview and left a permanent impression upon him, ${ }^{4}$ arguing that, "no man can live this life [of a nomad] and emerge unchanged...he will have within him the yearning to return...for this cruel land can cast a spell which no temperate climate can match." ${ }^{5}$ Nearly a century later, while the region still struggles to retain its romantic past against the constant advance of modernity, our own experiences during our design-build studio, Neonomads, echo Thesiger's, as for students and faculty the course blurred the boundaries between a singular, challenging educational experience and an intense physical and practical effort. While we constructed and sited multiple structures along the way, ultimately the studio became characterized less as a building project than as a process of negotiations between the known and the unknown, nature and society, the old and the new, and success and absolute failure, in which we often found ourselves between a rock and a hard place and, in some way, each of us was transformed.

By developing a project to sensitively construct and deploy a basic shelter, we hoped to allow people to get a little farther out to experience a little known people and place. As veritable outsiders, we began the project with no site, no client, and no community partner and a hunch that within the year we would engage the community and penetrate the desert, as few foreigners have done before. Eventually, we found a compelling site and designed, prototyped, and deployed a lightweight structure programmed to provide fundamental 


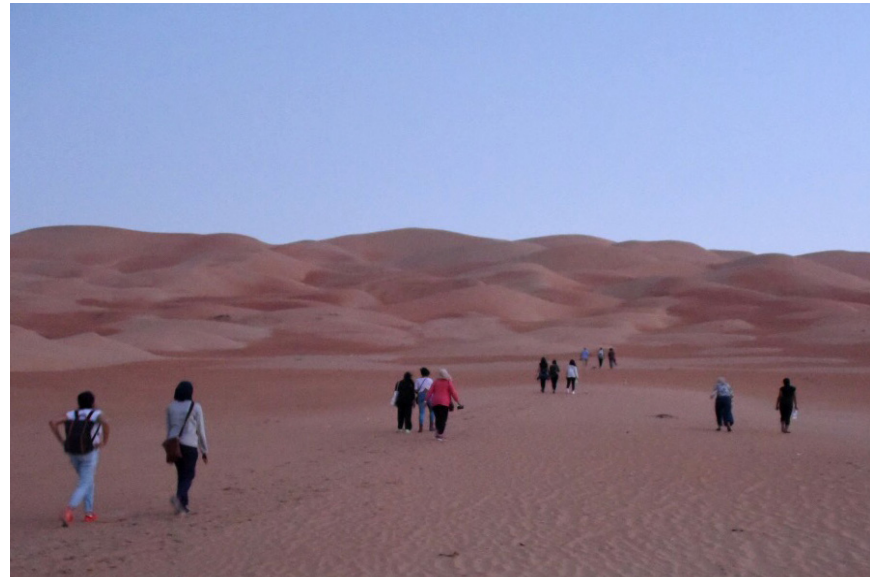

Figure 1. Students walking at the edge of the Rub' al Khali near Liwa during a joint studio visit. (Gregory Spaw)

protection from the elements including shade, access to water, fire, light, and basic communication with the outside world. We engaged students theoretically and practically in a set of discursive and contingent relationships, temporally, materially, logistically, and technologically, among others. We developed a richness of dialogue regarding sequence, staging, and the variability of architectural response as defined by the desert's diminishing ability to support human life over time and distance. Ultimately, students were confronted with the questions of what architecture is, basically, at is core; what it provides; and how, whether, or in what form it is fundamentally necessary, not just to live, but to exist.

\section{BETWEEN CULTURES}

The ancient Bedouin managed to survive for thousands of years living in the Empty Quarter of Oman, Yemen, Saudi Arabia and the UAE, surviving extreme heat and scarcity of food and water, without the need for high technology, and for most of that time with little contact with the outside world. ${ }^{6}$ The Emirati culture, also tribal and nomadic through the better half of the twentieth century, has raced toward modern development since discovering oil. Leaving their tribal past to form the country 45 years ago, they moved from tents and adobe to contemporary soaring skylines in a short time to become a major global player in finance, trade, and tourism, boasting a 2475\% increase in oil revenues between 1970 and 1975 alone. ${ }^{7}$ With an imported labor force, Emiratis now make up less than 11.5\% of the resident population, as Indians, Pakistanis, and other expatriates compose the majority, making it one of the most diverse populations in the region, if not the world. ${ }^{8}$ As the country developed, rather than actively and purposefully preserving their cultural heritage, the UAE left behind nomadic traditions and the Bedouin were assimilated into the new way of life. ${ }^{9}$ Additionally, through this rapid melting of cultures, the local building industry has evolved into a blurry and unconventional mosaic of traditional, natural, modern and artificial technologies, materials, and building methods, posing a challenge for two American faculty. Our student team, comprised of 31 women and 3 men from

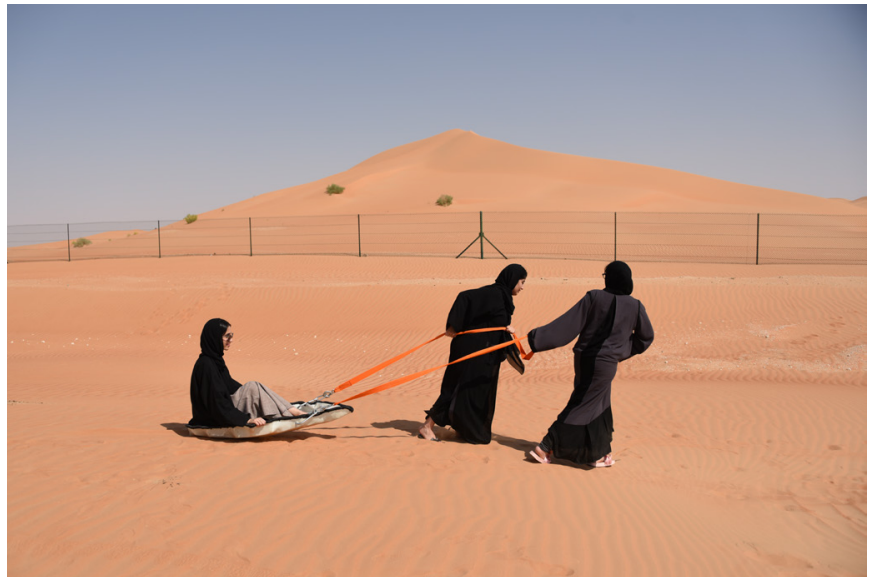

Figure 2. Testing of a deployment exercise prototype in the September heat of the Empty Quarter. (Gregory Spaw)

more than a dozen countries, were raised in modern cultures but found themselves connected to the Bedouin and the desert through a romantic and somewhat intangible notion of cultural heritage. The project was situated to both take advantage of the students' technologically savvy upbringing and ability to navigate the multiethnic, multilingual culture while providing them a vehicle to revisit, reinvestigate and, in some way, reimagine their ancient pasts.

Our initial intention was to site the project within the open expanse of the Empty Quarter as a demountable structure, but left in place for an indefinite period of time and accessible by the general public. We knew from research that temporary camping was lawful anywhere with the UAE on public land, and that permits for "winter camps" could be applied for, but are only available to Emiratis and for no longer than six months. ${ }^{10}$ Knowing that the artist Christo has been denied approval to site his artwork within the Empty Quarter for the past 40 years, ${ }^{11}$ we were not hopeful. We began by working with the Abu Dhabi Music and Arts Foundation (ADMAF) who connected us with Ahmed Al Yafei, founder of the Art Hub who had private property within the Rub' al Khali. During a visit to his property, we asked Al Yafei if it would be possible to locate our structure within the desert near his home, to which he tellingly responded with confusion and stated that, for local people, putting our project in the desert would be akin to placing a building "in the middle of the street." Frustrated, we decided to look closer to home. Working at the end of the fall semester with British ex-pat Peter Jackson, the Architectural Advisor to the Ruler of Sharjah, we were put in touch with John Pereira and Brendan Whittington-Jones of the EPAA, two South African environmental scientists who manage nine environmentally protected areas within the emirate of Sharjah, one of which would become our site in the spring.

Meanwhile, students working in two vertical fourth- and fifth -year studio sections were designing under the premise we would still be deploying our structures into the Empty Quarter. The program criteria they were given were minimal, requiring lightweight, modular, component parts able to be carried overland manually by one to two people, without the use of motorized vehicles. To this end, we 


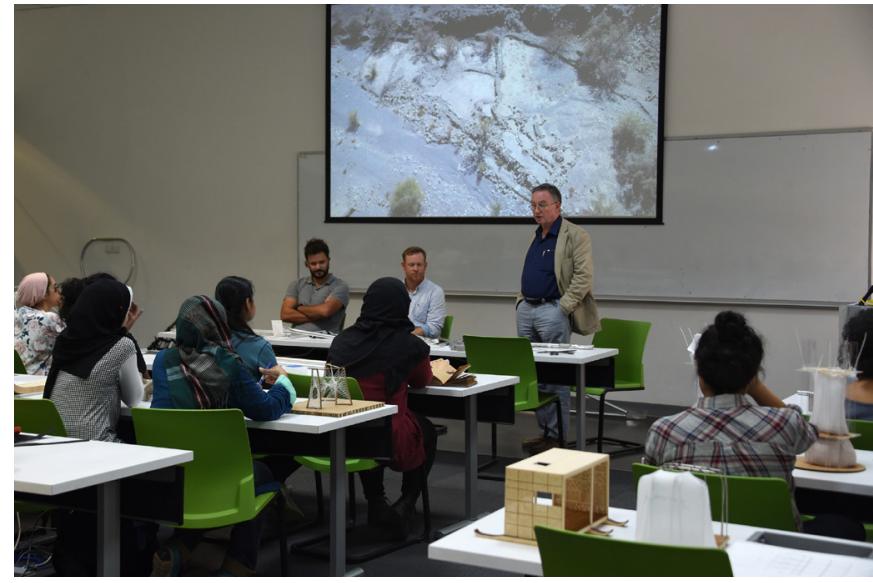

Figure 3. Initial project and Wadi Helo site discussion with John Pereira, Brendan Whittington-Jones, and Peter Jackson. (Gregory Spaw)

developed a deployment exercise early in the fall, asking students to design and fabricate working prototypes of conveyance systems to move building materials over a landscape of sand. Although this first exercise, based on Jack Mezirow's "disorienting dilemma" as the first step in transformational learning, ${ }^{12}$ was designed to introduce the students early to the idea of failure and the difficulty posed by the environment, primarily it was meant to encourage them to challenge the conventional notions and preconceptions they had already established about the nature of architecture. Little did we know then how similar and even more stringent the criteria for the project set by the EPAA would be and, once we were introduced to the building site, how valuable this first exercise would become.

\section{BETWEEN ENVIRONMENTS}

The Rub' al Khali is the largest open sand desert in the world, supports only the hardiest animal life, has little to no vegetation, and offers few sources of water. ${ }^{13}$ The deserts extend into the UAE and merge with a variety of other landscapes and ecosystems, including barren mountains scarred by seasonal wadis, iron rich red sand deserts, and mangrove thickets along the coast of the Arabian Gulf. ${ }^{14}$ As a tropical desert climate, there is little rainfall but high relative humidity due to the proximity to large bodies of water and, when combined with extreme high temperatures frequently above 115 degrees Fahrenheit/forty-six degrees Celsius during the summer months, being outside in the UAE can be deadly. ${ }^{15}$ Although historically hardened to living in these harsh conditions, the Bedouin and other local peoples have long since left behind unconditioned desert dwellings for the comforts of air conditioned buildings, including some of the highest skyscrapers and largest shopping malls in the world. The impact of shifting attitudes toward comfort and favoring artificial interior environments is evidenced in the built environment's rapid encroachment upon and, inevitably, the degradation and loss of natural ecosystems. ${ }^{16}$ Not surprisingly, many of our students are unaccustomed to being outdoors and most have never slept a night outside. Working with environmental scientists from the EPAA required us to

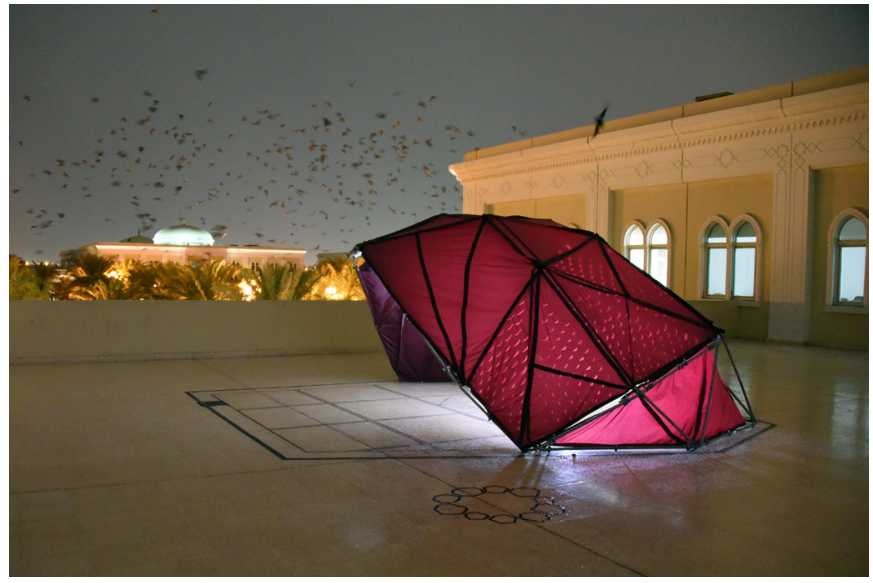

Figure 4. Full-scale looping and interweaving prototype produced during one of two fall Neonomads studios. (Gregory Spaw)

look back, ironically perhaps, to the simpler, lower tech traditions of the nomads, as the scientists often camp overnight in areas with no access to power or water and vehicular access to these sites is strictly prohibited. In this way, reintroducing the students to the ancient customs of laboring in the heat, sleeping under the stars, and walking with your home on your back became less a pedagogical constraint than a practical imperative.

In December, the EPAA asked us to place a two-person structure on a site two kilometers up a canyon wash in Wadi Helo, a protected area within the Hajar mountains referred to locally as the "olive highlands." Known for its 147 various species of birds, rodents, and reptiles, the valley is an "island" of biodiversity periodically washed with heavy rains. ${ }^{17}$ Embedded within this rich ecosystem is a complex infrastructure of archaeological ruins reminiscent of those found in Mesa Verde National Park, some dating back as far as 8000 BCE to the Neolithic and early Bronze Age, where evidence indicates the valley was a central location for copper smelting within the region. ${ }^{18}$ Due to these factors, the canyon is frequented by scientists of various disciplines conducting field research and is an ideal location for a shelter. Although we were enamored with the site and focused our efforts there for most of the spring semester, we were ultimately unable to secure permission to install a shelter by our deadline in April, and so were moved by the EPAA to an alternate site, a protected area known as Elebriddi. Coincidentally, the new site was also a two-kilometer hike from the entrance into the heart of a vast, beautiful landscape of ancient gravel-covered alluvial flood plains and acacia tree forests. Like Wadi Helo, due to Elebriddi's remote location, difficulty of terrain, and the amount of gear required for field trips, researchers are typically unable to pack in enough water to last more than a night. The structure would allow the EPAA and other scientists to carry in less gear and more water, supporting longer term site visits.

From December to midway through the spring, students designed specifically for conditions at the Wadi Helo site and made accommodations for two sleeping surfaces, a work table, built-in fire pit, storage for gear and instruments, and refrigeration and lighting powered by a solar array and $1250 \mathrm{Wh}$ generator. To prevent rodents from 


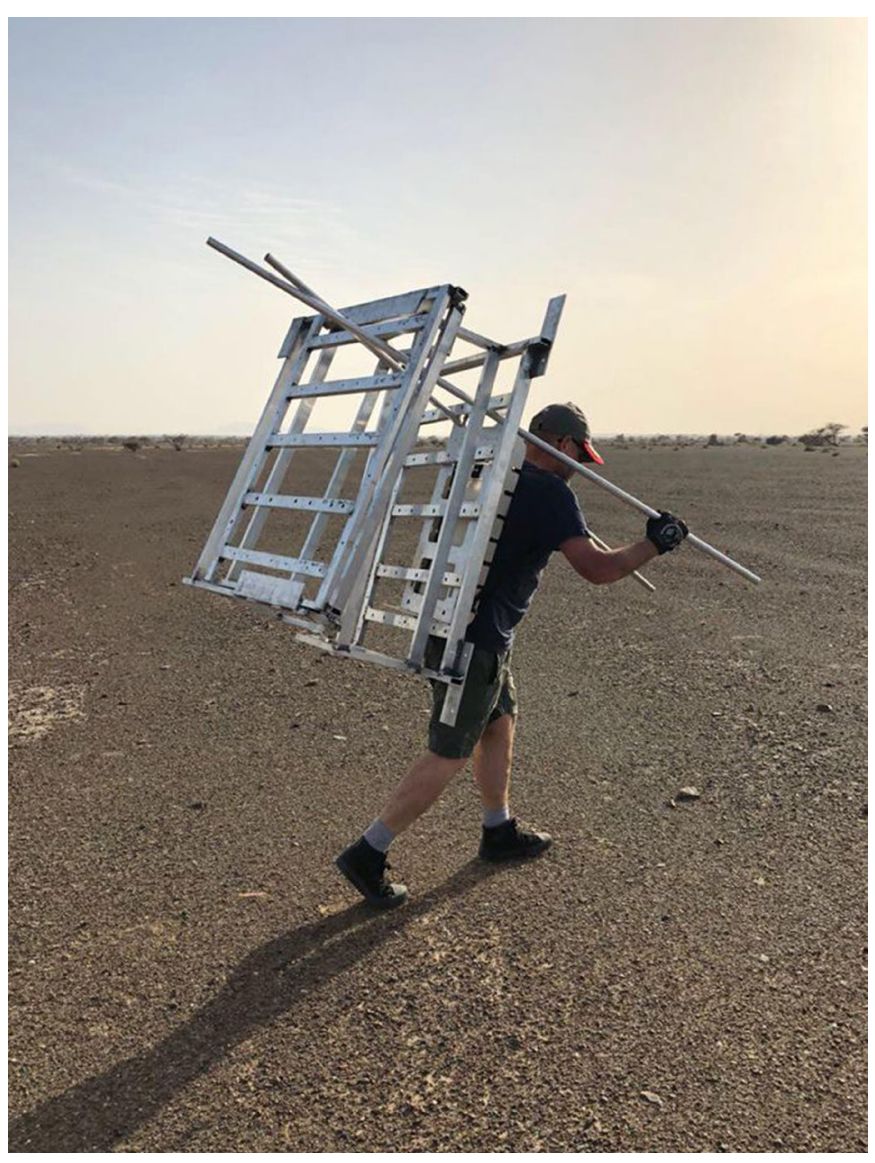

Figure 5. Deploying components at the Elebriddi site with custom fabricated backpacks and shoulder poles. (Lamya Alqassimi)

chewing through wires, all cables were sealed in flexible stainless steel conduits along their full lengths. Soil conditions in the wadi, hard packed sand containing large stones and some larger boulders, prevented us from securing the structure to the ground, so our initial plan to use lightweight aluminum screw anchors was scrapped. When the site was changed to Elebriddi, most of our design considerations developed for Wadi Helo were still pertinent and easily adapted, with the exception of a few critical factors. As wind was not much of a factor in the protected canyon of Wadi Helo, the superstructure was taller and boxier than what was appropriate for the much more open and windswept plains of Elebriddi. Considering the wind, the structure would ideally have been designed more aerodynamically and to be secured with anchors as the soil at Elebriddi is relatively loose sand. The change in site fairly late in the semester forced us to miss our window for early deployment and pushed it into the first two weeks in May, when late spring temperatures were already reaching above one hundred degrees Fahrenheit/thirty-eight degrees Celsius during the day. While both sites are inaccessible to vehicles, Wadi Helo's rocky ground would have allowed for the use of carts or other wheeled conveyances to aid us in deployment of the structure's components, but the softer sand at Elebriddi meant that the EPAA's restrictions on traveling overland were much more stringent, meaning no wheels

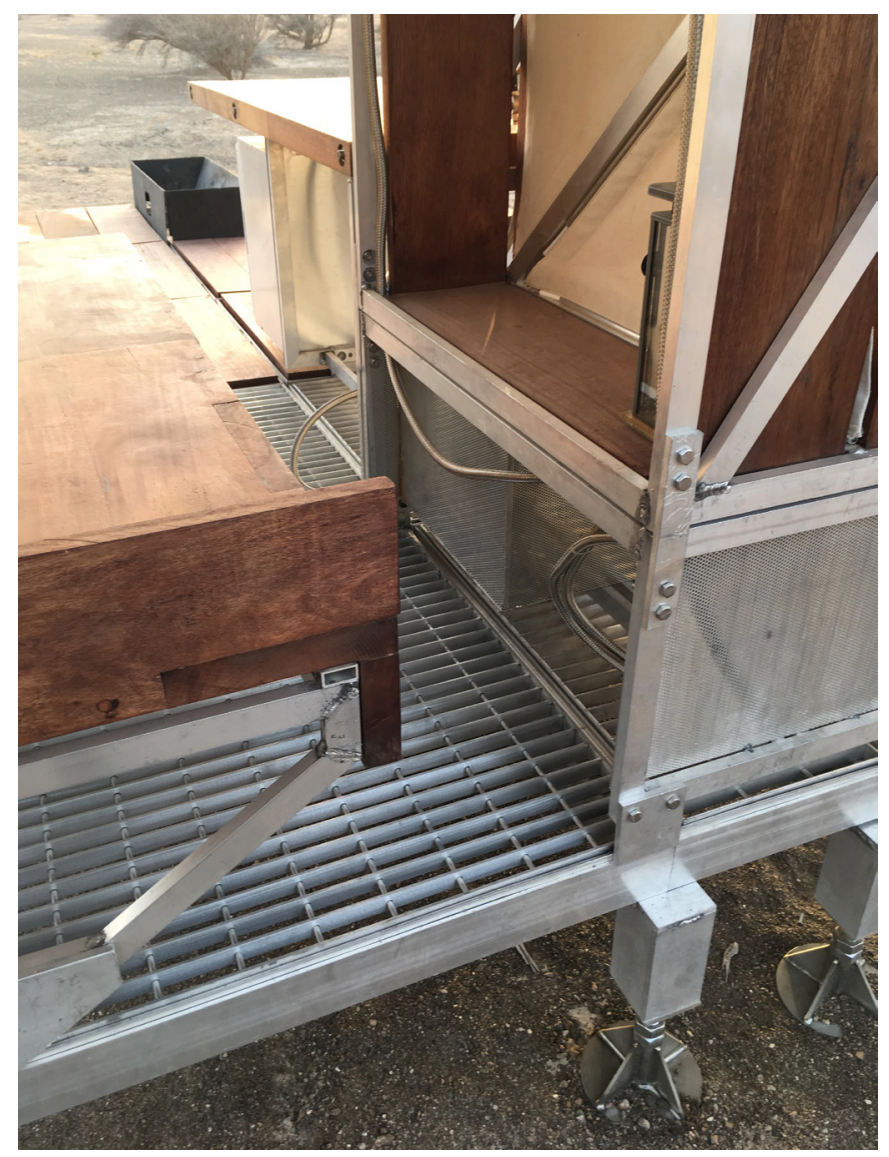

Figure 6. Detail of materials and components interface of the Elebriddi Neonomads shelter. (Patrick Rhodes)

of any kind could be used so as not to disturb the ground surface and leave tracks and traces behind. The lessons we learned during the deployment charrette at the beginning of the fall semester would come in handy as we adapted our deployment strategy, fabricating special backpacks and portable frames and using shoulder poles balanced between two people to carry heavier components.

\section{BETWEEN ARCHITECTURES}

As a collaborative effort, Neonomads, like many other design build projects, was inherently between architectures and architectural visions. It spanned two semesters, three studios, and was led by a team of two professors. In spite of this, the unique external challenges of the project and site(s) served as a cohesive reality, focusing both the students and faculty toward constructive decision-making. The initial deployment exercise and subsequent investigations of precedent informed the teams' multiple architectural proposals that, over the course of the three studios, each contributed toward the development and eventual construction of the Neonomads shelter among the acacia trees of the Elebriddi site. ${ }^{19}$ Collectively these efforts addressed issues of lightness and weight, mobility and persistence, and short-term goals and long-term vision. 


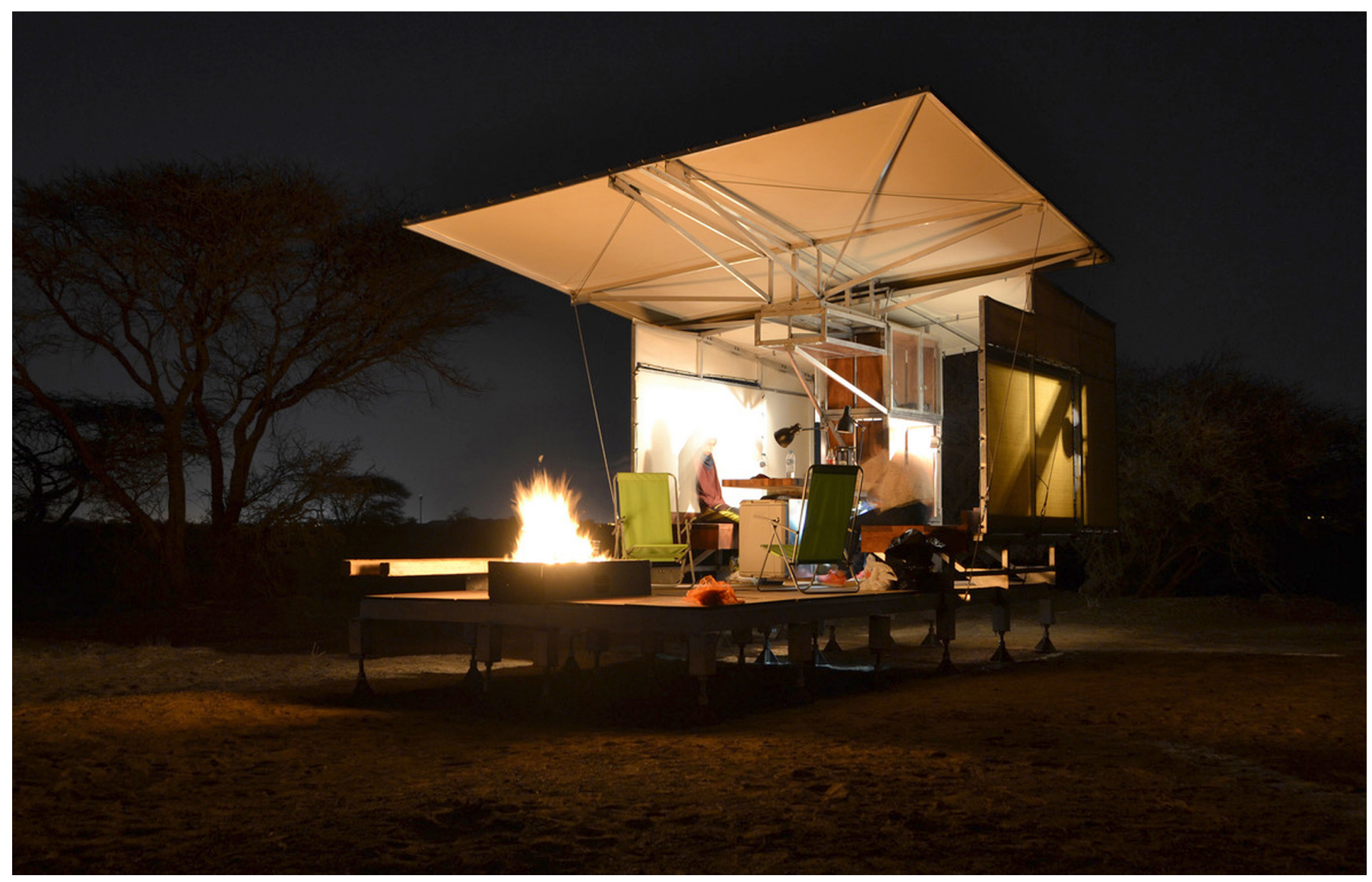

Figure 7. Night view of the installed Neonomads shelter among the acacia trees at the EPAA protected Elebriddi site. (Lamya Alqassimi)

Perhaps as a collective hunch, concerns of viability and durability informed the teams' related trajectories in material exploration across the studios. Both fall studios explored aluminum tube construction with one favoring interweaving and banding to the other's initial testing of MIG welding. Each also made use of digital fabrication tools to create jigs to facilitate fabrication accuracy and speed in conjunction with more traditional analog means. While each of the fall studios developed numerous tests and created full-scale prototypes, the contributions of the studios to the final project were as much about student skill sets and ways of thinking as they were about tangible connections, approaches to shading, and how the project meets the ground.

Starting with far greater clarity of problem and purpose, the spring studio benefitted from a cross section of students from each of the previous studios as well as a smattering of new blood. During this semester, the studio further investigated three distinct design approaches to the established program of sheltering two to three EPAA scientists for overnight research trips to the site(s) under their purview. After receiving critical feedback from Pereira and Whittington-Jones of the EPAA, the studio made the decision to move forward on a single design. The studio was thus allowed to refine certain aspects, such as materiality and connections, that were first investigated in the fall studios. It was also able to reimagine the overall geometry of the project, introducing a modular storage system and incorporating power generation via solar panels, which allowed for lighting, recharging of equipment, and refrigeration.

Throughout the design build, design considerations related to lightness and weight were of constant concern. The necessity of carrying and deploying the structure without detrimentally impacting the EPAA protected areas also meant components needed to be judged in terms of manageability and feasibility of construction on site. While many materials were initially considered over the course of the studios, aluminum was used as the primary structural material due to its strength to weight ratio and the students' acquired familiarity with it. MIG welding was employed to create modular elements that could be later bolted on site using simple hand tools. Mahogany and other recycled wood were selected to infill as flooring, resting, and storage surfaces due to their workability, renewability, and durability to the harsh desert conditions, as well as their ability to add ballast to the overall structure. Canvas provided overhead and lateral solar protection, serving as a final weight saving measure in terms of self-weight and consequently minimized associated structural member size.

While lightness and weight were critical to the deployment of the structure on site, the project also needed to negotiate between issues 
of mobility and persistence. This dichotomy was addressed in a number of ways. Due to the relative lightness of the construction material, the mobility of the project was appreciable as it could be rapidly disassembled, moved, and reassembled as the EPAA's research needs change over time. Mobility is apparent at the scale of the details as well. The project's base plates were designed to work on a series of soil conditions, while still allowing for individual leveling of the elevated platform across uneven terrain. The persistence of the project was as much about the students' experiences working through the initial adversity of unknowns related to client, site, and program as it was about finding and developing fabrication methods for quality craft of construction and the shelter's ability to withstand and hold up over time to the punishing realities of its immediate surroundings.

With the harsh realities of the desert ever present and the logistical challenges under serious consideration, the short-term architectural goals of the design-build were first and foremost one of shelter and survival. Over time, the team managed to work through these most essential of issues. Indeed, it further investigated technologies and incorporated equipment that allowed the researchers to stay in the field for longer as well as enjoy some small comforts on site. The Elebriddi project represents an important first step to moving beyond the edge of the desert, but the broader long-term architectural vision for the Neonomads is an ongoing endeavor to frame a transcendental experience in the isolated and pristine settings of the Arabian Desert.

\section{CONCLUSIONS}

In terms of learning outcomes and "building a better bridge between the academy and the profession," 20 the benefits of design-build are generally accepted, but by its very nature design-build is neither a purely academic exercise nor fully representative of the methodologies of the design and building practices. And yet because of this otherness, in between the silos of the academy, practice, and the building trades, utilizing design-build as a process challenged the participants and garnered a multifaceted educational experience that dialectically negotiated between a series of cultural, environmental, and architectural extremes. While still working toward our ultimate goals, this assessment evidences both the successes and failures of the pedagogical and practical strategies thus far implemented and further reveals the capacity of design-build to foster equilibrium between teaching and practice while actively engaging the community more broadly.

\section{Notes}

1. Petraglia, Michael D., and Jeffrey I. Rose. The evolution of human populations in Arabia. Springer, Dordrecht, Netherlands, 2009: 10.

2. Edgell, H. Stewart. Arabian deserts: nature, origin and evolution. Springer Science \& Business Media, 2006: 127.

3. Thesiger, Wilfred. "A new journey in southern Arabia." The Geographical Journal 108.4/6 (1946): 129-145.

4. Moroz, Grzegorz, ed. Metamorphoses of travel writing: across theories, genres, centuries and literary traditions. Cambridge Scholars Publishing, 2010: 167.

5. Haynes, Roslynn D. Desert: Nature and culture. Reaktion Books, 2013: 125 - 151.

6. Webster, Roger. "Notes on the dialect and way of life of the Al Wahiba bedouin of Oman." Bulletin of the School of Oriental and African Studies 54.3 (1991): 473-485.

7. Al Sadik, Ali Tawfi. "Evolution and Performance of the UAE Economy 1972-1998." Ministry of Information and Culture, United Arab Emirates: A new perspective (2001): 202-230.

8. Global Media Insight. Expatriate Population of the UAE in 2018 (2019) Retrieved from https://www.globalmediainsight. com/blog/uae-population-statistics/

9. Hawker, Ronald W. "Imagining a Bedouin past: Stereotypes and cultural representation in the contemporary United Arab Emirates." LAU Publications of the Beirut Institute for Media Arts (2002).

10. Zaki, Yousra. "Camping in the UAE: Your ultimate guide." Gulf News, Dubai, 25 December 2018. Web: https://gulfnews.com/going-out/society/ camping-in-the-uae-your-ultimate-guide-1.1545728195812

11. Corkery, Claire. "Christo on his Abu Dhabi desert dream: 'I hope to do the project before I die'." The National, Abu Dhabi, 25 June 2018. Web: https://www.thenational.ae/arts-culture/ art/christo-on-his-abu-dhabi-desert-dream-i-hope-to-dothe-project-before-i-die-1.743892

12. Sill, David, Brian M. Harward, and Ivy Cooper. "The disorienting dilemma: The senior capstone as a transformative experience." Liberal Education 95.3 (2009): 50-55.

13. Vincent, Peter. Saudi Arabia: an environmental overview. CRC Press, 2008, 141-144.

14. Ouis, Pernilla. "'Greening the Emirates': the modern construction of nature in the United Arab Emirates." cultural geographies 9.3 (2002): 334-347.

15. Böer, Benno. "An introduction to the climate of the United Arab Emirates." Journal of arid environments 35.1 (1997): 3-16.

16. Gardner, Andrew, and Brigitte Howarth. "Urbanisation in the United Arab Emirates: the challenges for ecological mitigation in a rapidly developing country." BioRisk 3 (2009): 27.

17. Feulner, Gary R. "The Olive Highlands: A unique" island" of biodiversity within the Hajar Mountains of the United Arab Emirates." Tribulus 22 (2014): 9-35.

18. Uerpmann, Margarethe, et al. "HLO 1-south: An Early Neolithic site in Wadi al-Hilo (Sharjah, UAE)." Arabian Archaeology and Epigraphy 29.1 (2018): 1-9.

19. Environment and Protected Areas Authority. Elebriddi (2019) Retrieved from http://www.epaashj.ae/ protected-areas/elebriddi/

20. Kraus, Chad. Designbuild Education. Routledge, 2017, 21. 